Vietnam Journal of Mechanics, VAST, Vol. 27, No. 2 (2005), pp. 118-128

\title{
IDENTIFICATION PARAMETERS OF MATERIAL MODEL AND LARGE DEFORMATION ANALYSIS OF INFLATED AIR-SPRING SHELL MADE OF RUBBER-TEXTILE CORD COMPOSITE .
}

\author{
Tran HuU NAM \\ Hanoi University of Technology
}

\begin{abstract}
In the paper an orthotropic hyperelastic constitutive model is presented which can be applied to numerical simulation for the response of biological soft tissue and of the nonlinear anisotropic hyperelastic material of the cylindrical air-spring shell used in vibroisolation of driver's seat. The parameters of strain energy function of the proposed constitutive model are fitted to the experimental results by the nonlinear least squares method. The deformation of the inflated cylindrical air-spring shell is calculated by solving the system of five first-order ordinary differential equations with the material constitutive law and proper boundary conditions. Numerical results of principal stretches and deformed profiles of the inflated cylindrical air-spring shell obtained by numerical deformation analysis are compared with experimental ones.
\end{abstract}

Key words: constitutive model, rubber-textile cord composite, air-spring shell

\section{INTRODUCTION}

The composite materials created of rubber matrix reinforced by textile cords is called rubber-textile cord composites. Air-springs form an example of layered multiphase flexible composite structures that consist of rubbery matrix and stiff reinforcement made of textile cords. The high modulus, low elongation cords carry most of the load, and the low modulus, high elongation rubber matrix preserves the integrity of the composite and transfers the load. The primary objective of this type composite is to withstand large deformation and fatigue loading while providing high load carrying capacity.

Recently, classical phenomenological constitutive equations for rubber-like solids, such as Mooney-Rivlin, Neo-Hookean or Ogden models (Beatty, 1987; Holzapfel et al, 2000; Bonet \& Profit, 2000; Guo, 2001) are progressively replaced by more physical models based on statistical considerations in various engineering applications. The identification of material parameters of the constitutive models is often performed using classical homogeneous strain experiments (uniaxial extension or pure shear tests for example). For biaxial deformation, authors use frequently the bubble inflation technique, that consists in inflating an initially plane circular thin membrane (Verron \& Marckmann, 2003). In this type of experiments, deformations are not homogeneous and the analysis of experimental data needs efficient numerical method to solve the inflation problem.

Motivated mainly by interest in the numerical simulation of hyperelastic materials some orthotropic and transversely hyperelastic constitutive models have been proposed recently. Most of them are represented by strain energy function formulated as a polynomial (Bonet \& Burton, 1998) or an exponential (Ogden et al, 2000; Holzapfel et al, 2000, 2001) or logarithmic function (Poživilová \& Plešek, 2002) of orthotropic (or transversely isotropic) strain invariants. However, the development of the constitutive theory of anisotropic elastic or viscoelastic materials at finite strains is still far to be completed and 
the publications in this field are sparse. For the isotropic hyperelastic materials, the Ogden model with a strain energy function formulated in terms of principal stretches has been shown to be of advantage in spite of a relatively complicated numerical realization. This model demonstrates an excellent agreement with experimental results at large strains and involves many other material laws, for example Mooney-Rivlin and Neo-Hookean ones as special case. Therefore, the orthotropic generalization of Ogden model enables to consider various anisotropic hyperelastic materials within a unified concept.

The main purpose of the framework paper is identification parameters of the proposed orthotropic hyperelastic constitutive model and large deformation analysis of the inflated cylindrical air-spring shell made of rubber-textile cord composites.

\section{DESCRIPTION OF STRUCTURAL MATERIAL AND EXPERIMENTAL ANALYSIS}

An air-spring shell (Fig.1) is usually made up of four layers - the inner and the outer layer of calandered rubber and the two plies of cord reinforced rubber in which the cords have a specific bias angle to the other arranged symmetrically with respect to the circumferential direction (Fig. 2).
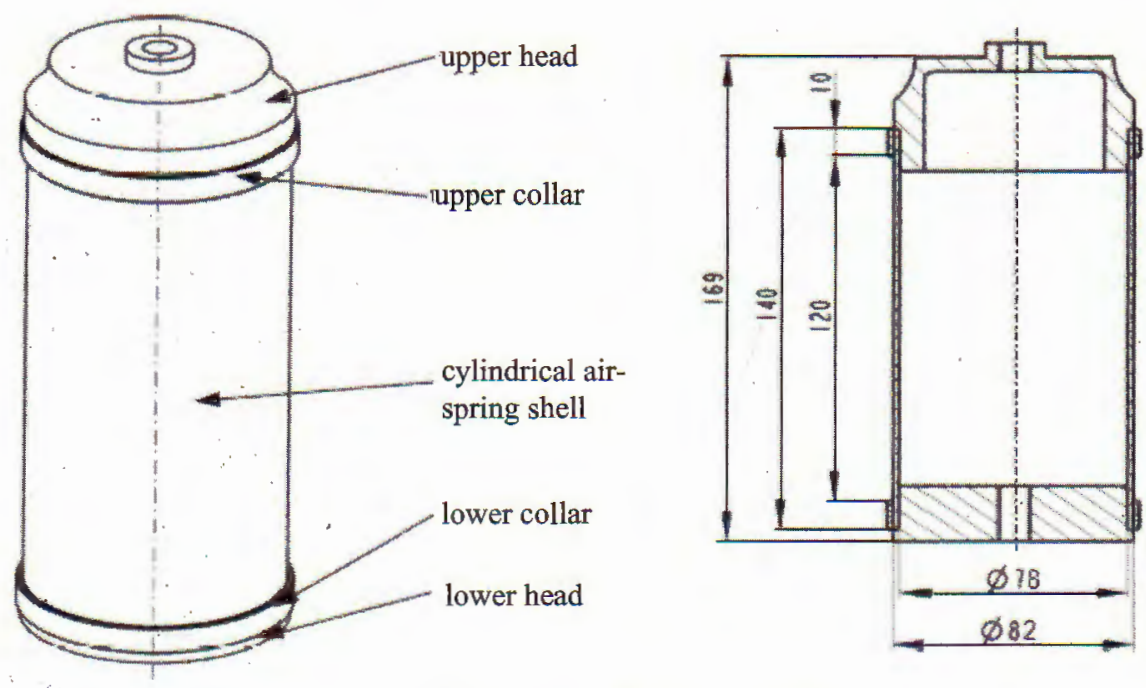

Fig. 1. Cylindrical air-spring shell

The resulting material properties are orthotropic in the case of in-axis loading. The cylindrical air-spring is relatively short - the diameter of the tubular shell is $2 \mathrm{R}=82 \mathrm{~mm}$, the height is $L=120 \mathrm{~mm}$ and the wall thickness is $H=2 \mathrm{~mm}$. The properties of the material and the angle between cords have to be determined experimentally in site since the air-spring is assigned for further experiments and it cannot be dissected for usual material tests.

The experimental tests were carried out at five different positions of the air-spring. First the mounting plates of the non-loaded air-spring were fixed at the distance by 15 , $20,30,40$ or $50 \mathrm{~mm}$ shorter than the free height of the air-spring. Then the air-spring was loaded and unloaded gradually by pressurized air step $0.05 \mathrm{MPa}$ in the range $0.1-0.5 \mathrm{MPa}$. 
Photographs of the deformed sheet were recorded by digital camera, the axial force and the inner pressure were measured and stored at every stage of loading. Digital photographs were processed semi-automatically by means of the Matlab image processing toolbox. The centroids of deformed grid spots were calculated and the coordinates of contour points of the deformed air-spring shell were recorded. The deformations of air-spring shell are determined from the photographic records of the deformed grid of points drawn on the surface of air-spring shell through digital image processing techniques. Details on the experimental setup and the experiment evaluations can be found in the previous papers of Marvalova (Marvalova et al, 2001, 2002)
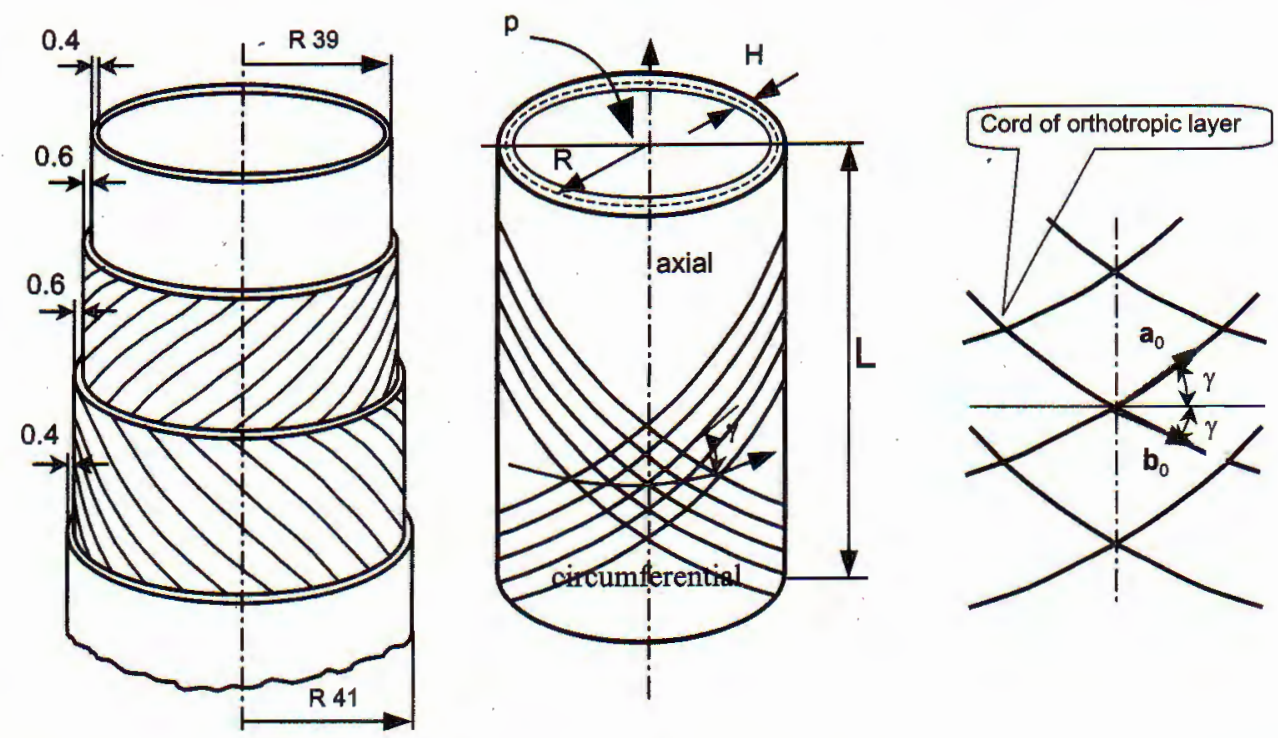

Fig. 2. Textile cord reinforced circular tube of cylindrical air-spring. Continuum model for the structure of the orthotropic layer (with double-helically arranged fibers).

\section{DEFORMATION OF INFLATED CYLINDRICAL MEMBRANE}

The main geometric features of the inflated membrane in according writh the derivation of the works (Guo, 2001) are determined. The cylindrical air-spring shell at Fig. 3 has the initial radius of mid-surface $R$, and length $L$. Its initial wall thickness $H$ is assumed to be uniform. The undeformed profile of membrane is described by polar coordinate system, $(X, \Phi, R)$. The cylindrical membrane is inflated by the internal pressure $p$.

The deformed cylindrical membrane is referred to the polar coordinate system $(x, \phi$, $r)$. A material particle moves during the deformation from the position in the undeformed profile, $C(X, \Phi, R)$ to the deformed profile, $c(x, \phi, r)$, along its quasi-equilibrium path. Assume that the deformation is axisymmetric, then $\phi \equiv \Phi$. The principal stretch in axial and circumferential directions, principal curvatures and geometric relations are

$$
\lambda_{1}=\frac{d s}{d S}, \quad \lambda_{2}=\frac{r}{R}, \quad \frac{d r}{d s}=-\sin \theta, \quad \frac{d x}{d s}=\cos \theta, \quad \kappa_{1}=\frac{d \theta}{d s}, \quad \kappa_{2}=\frac{\cos \theta}{r}
$$


where $s$ is the arc length measured from pole $(x=0)$ to the particle $c(x, \phi, r)$ along the meridian of the deformed profile. $S$ is the length corresponding to $s$ in the undeformed profile. An auxiliary variable $\theta$ is introduced through the angle of the tangent line. The radius $r$ and the thickness $h$ of the membrane are with respect to the deformed configuration. The radial stretch $\lambda_{3}$ is determined from the incompressibility constraint.

then

$$
\begin{aligned}
& \lambda_{1} \lambda_{2} \lambda_{3}=1 \\
& h=\frac{H}{\lambda_{1} \lambda_{2}}
\end{aligned}
$$

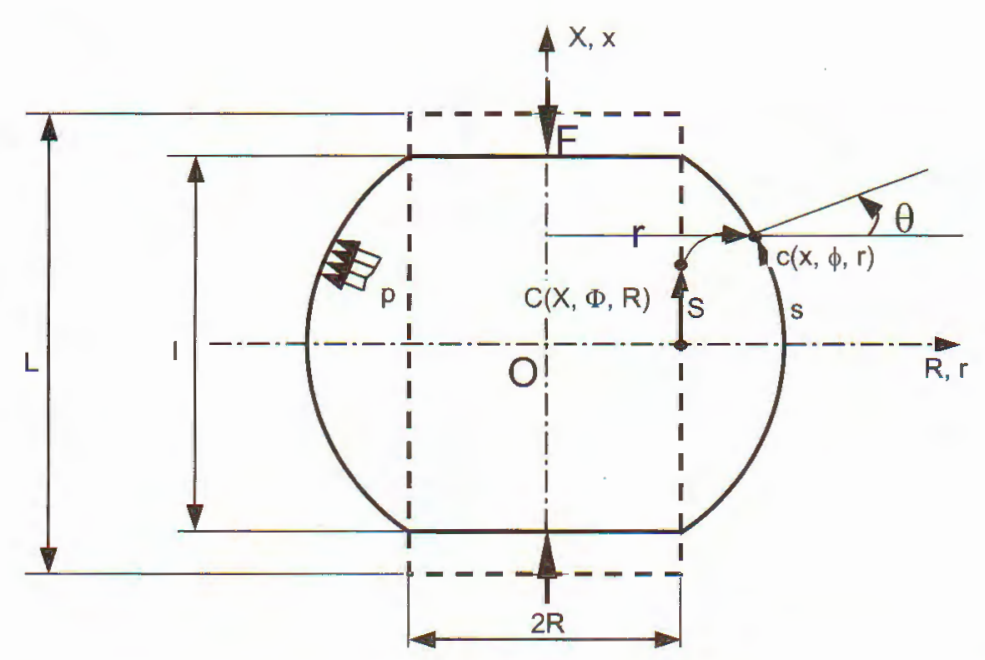

Fig. 3. Undeformed and deformed profile of inflated cylindrical membrane

\section{THE PROPOSED ORTHOTROPIC HYPERELASTIC CONSTITUTIVE MODEL}

The formulation of the anisotropic constitutive model has the main advantage that all involved material parameters may be associated with the material constituents, i.e. matrix materials and the fibers. The orthotropic hyperelastic materials in this paper are considered incompressible composite materials with two families of fibers. Let's assume the isochoric deformation and neglect the dissipation due to irreversible effects. The free energy of the orthotropic hyperelastic materials considered is stored in the matrix material and fibers. Thus, a proposed strain energy function considered the combination of scalarvalue functions corresponding to energy stored in matrix material and the fibers parts.

$$
\Psi=\Psi_{\text {iso }}+\Psi_{\text {aniso }},
$$

where $\Psi_{\text {iso }}$ is the component of strain energy function for isotropic properties of materials. $\Psi_{\text {aniso }}$ is the component of strain energy function for anisotropic properties.

The isotropic component of strain energy function may be involved by the strain energy function of Ogden's model (Ogden, 2001) as

$$
\Psi_{i s o}=\Psi_{i s o}\left(\lambda_{1}, \lambda_{2}, \lambda_{3}\right)=\sum_{n=1}^{3} \frac{\mu_{n}}{\alpha_{n}}\left(\lambda_{1}^{\alpha_{n}}+\lambda_{2}^{\alpha_{n}}+\lambda_{3}^{\alpha_{n}}-3\right)
$$


where $\lambda_{1}, \lambda_{2}$, and $\lambda_{3}$ are the three principal stretches. The parameters $\mu_{n}$ and $\alpha_{n}$ of Ogden's model of rubber (Holzapfel, 2000) are

$$
\begin{aligned}
& \mu_{1}=0.63 M P a, \quad \mu_{2}=0.0012 M P a, \quad \mu_{3}=-0.01 M P a, \\
& \alpha_{1}=1.3, \quad \alpha_{2}=5, \quad \alpha_{3}=-2 .
\end{aligned}
$$

Suppose that the reinforcing fibers are double-helically arranged in the matrix material symmetrically to the circumferential direction then the component of strain energy function for anisotropic property is expressed in terms of principal stretches in the form of exponential function

$$
\Psi_{\text {aniso }}=\frac{k_{1}}{k_{2}}\left\{\exp \left[k_{2}\left(\lambda_{2}^{2} \cos ^{2} \gamma+\lambda_{1}^{2} \sin ^{2} \gamma-1\right)^{2}\right]-1\right\}
$$

where $2 \gamma$ is the angle of the two families of reinforced fibers, $\mathbf{k}_{1}$ is stress-like material parameter and $k_{2}$ is a dimensionless parameter (Holzapfel \& Gasser, 2001). They are determined from the experimental results and from the $2 \mathrm{D}$ cylindrical membrane approximation. The angle $\gamma$ of fibers is supposed to be $48.8^{\circ}$.

The strain energy stored in the fibers is assumed to be governed by an exponential function described above. The strain energy function with the component for isotropic properties of Ogden's model in two dimensional problem with incompressibility constraint can be supposed in the form

$$
\begin{aligned}
\Psi\left(\lambda_{1}, \lambda_{2}\right)= & \sum_{n=1}^{3} \frac{\mu_{n}}{\alpha_{n}}\left(\lambda_{1}^{\alpha_{n}}+\lambda_{2}^{\alpha_{n}}+\lambda_{1}^{-\alpha_{n}} \lambda_{2}^{-\alpha_{n}}-3\right)+ \\
& +\frac{k_{1}}{k_{2}}\left\{\exp \left[k_{2}\left(\lambda_{2}^{2} \cos ^{2} \gamma+\lambda_{1}^{2} \sin ^{2} \gamma-1\right)^{2}\right]-1\right\}
\end{aligned}
$$

\section{IDENTIFICATION OF MATERIAL PARAMETERS}

Constitutive equations are the stress-strain relationships for the deformed membrane. If the strain energy function $\Psi$ is an invariant, we may regard $\Psi$ as a function of the principal stretches $\lambda_{a}(a=1,2,3)$. In engineering practice, such an equation can be represented by strain energy function, $\Psi\left(\lambda_{1}, \lambda_{2}, \lambda_{3}\right)$. The principal Cauchy stresses associated with this deformation are given from strain energy function (Holzapfel, 2000)

$$
\sigma_{a}=-p^{*}+\lambda_{a} \frac{\partial \Psi}{\partial \lambda_{a}}, \quad a=1,2,3
$$

where $p^{*}$ is the indeterminate Lagrange multiplier (hydrostatic pressure). The relationships of the invariants $I_{1}, I_{2}$ and $I_{3}$ and principal stretches are also defined in the form.

$$
\begin{aligned}
& I_{1}=\lambda_{1}^{2}+\lambda_{2}^{2}+\lambda_{3}^{2} \\
& I_{2}=\lambda_{1}^{2} \lambda_{2}^{2}+\lambda_{2}^{2} \lambda_{3}^{2}+\lambda_{3}^{2} \lambda_{1}^{2} \\
& I_{3}=\lambda_{1}^{2} \lambda_{2}^{2} \lambda_{3}^{2}
\end{aligned}
$$


By regarding inflation two of the stretches as dependent and treating the strain energy as a function of these through the definition $\Psi\left(\lambda_{1}, \lambda_{2}\right)$, the constitutive equations are obtained

$$
\begin{aligned}
& \sigma_{1}-\sigma_{3}=\lambda_{1} \frac{\partial \Psi\left(\lambda_{1}, \lambda_{2}\right)}{\partial \lambda_{1}}, \\
& \sigma_{2}-\sigma_{3}=\lambda_{2} \frac{\partial \Psi\left(\lambda_{1}, \lambda_{2}\right)}{\partial \lambda_{2}}, \\
& \sigma_{2}-\sigma_{1}=\lambda_{2} \frac{\partial \Psi\left(\lambda_{1}, \lambda_{2}\right)}{\partial \lambda_{2}}-\lambda_{1} \frac{\partial \Psi\left(\lambda_{1}, \lambda_{2}\right)}{\partial \lambda_{1}} .
\end{aligned}
$$

The theory of nonlinear membranes has been presented by Green and Adkins (1965) and applied to various inflated structures (Guo, 2001). The quasi-static equilibrium equations of problem are

$$
\begin{aligned}
& \frac{d}{d s}\left(T_{1} r\right)=T_{2} \frac{d r}{d s}, \\
& \kappa_{1} T_{1}+\kappa_{2} T_{2}=p .
\end{aligned}
$$

where $T_{1}$ and $T_{2}$ are the stress resultant forces per unit length of the meridional and circumferential directions. $\kappa_{1}$ and $\kappa_{2}$ are principal curvatures for the deformed membrane surface (3.1). Suppose that $\sigma_{1}$ and $\sigma_{2}$ are the principal Cauchy stress at the particle. According to the assumptions for the membrane theory (Green Adkins, 1965), the stress resultant forces in the deformed configuration are

$$
\begin{aligned}
& T_{1}=h\left(\sigma_{1}-\sigma_{3}\right), \\
& T_{2}=h\left(\sigma_{2}-\sigma_{3}\right) .
\end{aligned}
$$

The stress resultant forces in the deformed configuration when neglected $\sigma_{3}$ are

$$
\begin{aligned}
& T_{1}=h \sigma_{1}, \\
& T_{?}=h \sigma_{2},
\end{aligned}
$$

where Cauchy stresses $\sigma_{1}$ and $\sigma_{z}$ are given by (5.1).

The experimental series of the inflated cylindrical air-spring with the variable axial force $F$ and the inner pressure $p$ are effectuated. The Cauchy stress is determined from the equilibrium in Fig. 4

$$
N_{1} \cos \theta=p \pi r^{2}-F \quad \Rightarrow \quad \sigma_{1}=\frac{p \pi r^{2}-F}{2 \pi r h \cos \theta}
$$

By substituting $r=\lambda_{2} R$ and $h=H / \lambda_{1} \lambda_{2}$ from (3.1) and (3.3) into (5.7) the stress $\sigma_{1}$ is obtained as

$$
\sigma_{1}=A \frac{1}{\cos \theta} \lambda_{1}\left(\lambda_{2}^{2}-B\right),
$$


in which

$$
A=\frac{p R}{2 H}, \quad B=\frac{F}{\pi p R^{2}}
$$

The stress $\sigma_{2}$ can be derived from equilibrium equations (5.4) and (5.5) in the following form

$$
\sigma_{2}=\frac{1}{\kappa_{2}}\left(\frac{p}{h}-\kappa_{1} \sigma_{1}\right)
$$

The stress $\sigma_{2}$ can be obtained by substitution of $h$ from (3.1) and $\sigma_{1}$ from (5.6) into $(5.10)$

$$
\sigma_{2}=\frac{p R}{H \cos \theta} \lambda_{1} \lambda_{2}^{2}-\frac{p}{2 H}-\frac{1}{\cos \theta} \lambda_{1}\left(\lambda_{2}^{2} R-\frac{F}{\pi R p}\right) \frac{\kappa_{1}}{\kappa_{2}}
$$

According to the theory of inflated membrane the stress $\sigma_{3}$ is assumed equal $-p$.

After the substitution of the Cauchy stresses into equations (5.2) a set of the nonlinear equations for the two variables $k_{1}$ and $k_{2}$ with the strain energy function presented in equation (4.4) is obtained as

$$
\begin{aligned}
& \sum_{n=1}^{3} \mu_{n}\left[\lambda_{1}^{\alpha_{n}}-\left(\lambda_{1} \lambda_{2}\right)^{-\alpha_{n}}\right]+4 k_{1} \exp \left(k_{2} m^{2}\right) m \lambda_{1}^{2} \sin ^{2} \alpha=C+p \\
& \sum_{n=1}^{3} \mu_{n}\left[\lambda_{2}^{\alpha_{n}}-\left(\lambda_{1} \lambda_{2}\right)^{-\alpha_{n}}\right]+4 k_{1} \exp \left(k_{2} m^{2}\right) m \lambda_{2}^{2} \cos ^{2} \alpha=p(D+1)-C \frac{\kappa_{1}}{\kappa_{2}} \\
& \sum_{n=1}^{3} \mu_{n}\left[\lambda_{2}^{\alpha_{n}}-\lambda_{1}^{\alpha_{n}}\right]+4 k_{1} \exp \left(k_{2} m^{2}\right) m\left(\lambda_{2}^{2} \cos ^{2} \alpha-\lambda_{1}^{2} \sin ^{2} \alpha\right)=p D-C\left(1+\frac{\kappa_{1}}{\kappa_{2}}\right)
\end{aligned}
$$

where

$$
C=\frac{p}{2 H} \frac{1}{\cos \theta} \lambda_{1}\left(\lambda_{2}^{2} R-\frac{F}{\pi R p}\right), D=\frac{p R}{H \cos \theta} \lambda_{1} \lambda_{2}^{2}, m=\lambda_{2}^{2} \cos ^{2} \alpha+\lambda_{1}^{2} \sin ^{2} \alpha-1 .
$$

The experimentally measured values of $\lambda_{1}$ and $\lambda_{2}$ in several points of the central part of our cylindrical membrane were substituted into the equations (5.12). Taking the logarithm of (5.12) we will get a set of linear equations for the variables $\ln k_{1}$ and $k_{2}$. The resulting overdetermined system of linear equations was solved in Matlab. The result of parameters in my calculated program were $k_{1}=41.87 \mathrm{MPa}$ and $k_{2}=$ -23.77. The function of the Helmholtz energy potential for these parameters is convex.

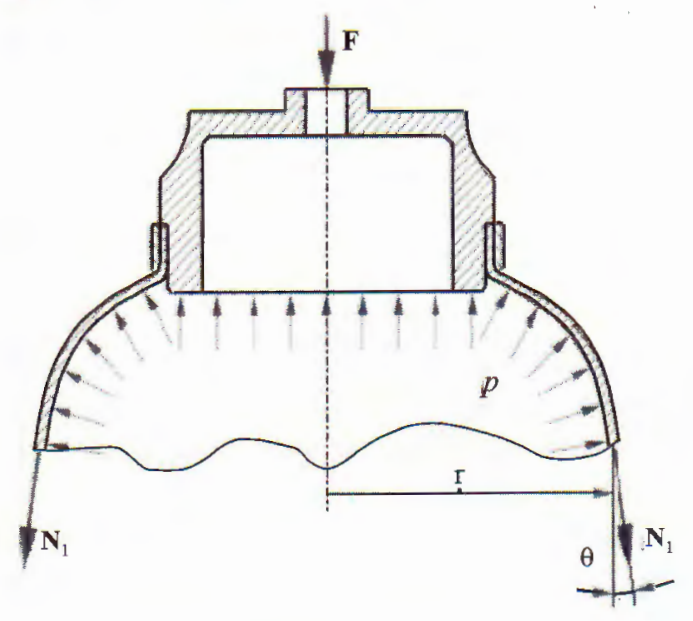

Fig. 4. The equilibrium of inflated cylindrical air-spring under loads 


\section{LARGE DEFORMATION ANALYSIS BY NUMERICAL INTEGRATION}

After the substitution of (3.1), (3.3), (5.1) and (5.5) into equilibrium equations of (5.3) and (5.4) and by some simplifications the system of five ordinary differential equations for the principal stretches $\lambda_{1}$ and $\lambda_{2}$, the tangent angle $\theta$, the coordinate $x$ in the deformed configuration and the inner pressure $p$ with respect to the coordinate $X$ of the undeformed configuration is obtained as

$$
\begin{aligned}
\frac{d \lambda_{1}}{d X}= & \frac{1}{\frac{A}{\cos \theta}\left(\lambda_{2}^{2}-B\right)-M}\left[\frac{\lambda_{1} \sin \theta}{R}\left(N-A \frac{2}{\cos \theta} \lambda_{1} \lambda_{2}\right)+A \frac{\sin \theta}{\cos ^{2} \theta} \lambda_{1}\left(\lambda_{2}^{2}-B\right) Q\right] \\
\frac{d \lambda_{2}}{d X}= & -\lambda_{1} R^{-1} \cdot \sin \theta \\
\frac{d \theta}{d X}= & \frac{1}{R} \frac{\cos \theta}{A\left(\lambda_{2}^{2}-B\right)}\left\{\frac { \operatorname { c o s } \theta } { \lambda _ { 2 } } \left[-p+\sum_{n=1}^{3} \mu_{n}\left(\lambda_{2}^{\alpha_{n}}-\left(\lambda_{1} \lambda_{2}\right)^{-\alpha_{n}}\right)+\right.\right. \\
& \left.\left.+4 k_{1} \exp \left(k_{2} m^{2}\right) m \lambda_{2}^{2} \cos ^{2} \alpha\right]-2 A \lambda_{1} \lambda_{2}\right\} \\
\frac{d x}{d X}= & \lambda_{1} \cdot \cos \theta, \\
\frac{d p}{d X}= & 0,
\end{aligned}
$$

where

$$
\begin{aligned}
Q= & \frac{1}{R} \frac{\cos \theta}{A\left(\lambda_{2}^{2}-B\right)}\left\{\frac { \operatorname { c o s } \theta } { \lambda _ { 2 } } \left[-p+\sum_{n=1}^{3} \mu_{\omega_{n}}\left(\lambda_{2}^{\alpha_{n}}-\left(\lambda_{1} \lambda_{2}\right)^{-\alpha_{n}}\right)+\right.\right. \\
& \left.\left.+4 k_{1} \exp \left(k_{2} m^{2}\right) m \lambda_{2}^{2} \cos ^{2} \alpha\right]-2 A \lambda_{1} \lambda_{2}\right\} \\
M= & \frac{1}{\lambda_{1}} \sum_{n=1}^{3} \mu_{n} \alpha_{n}\left[\lambda_{1}^{\alpha_{n}}+\left(\lambda_{1} \lambda_{2}\right)^{-\alpha_{n}}\right]+ \\
& +8 k_{1} \exp \left(k_{2} m^{2}\right) \lambda_{1} \sin ^{2} \alpha\left[\lambda_{1}^{2} \sin ^{2} \alpha\left(2 k_{2} m^{2}+1\right)+m\right] \\
N= & \frac{1}{\lambda_{2}} \sum_{n=1}^{3} \mu_{n} \alpha_{n}\left(\lambda_{1} \lambda_{2}\right)^{-\alpha_{n}}+8 k_{1} \exp \left(k_{2} m^{2}\right) \lambda_{1}^{2} \lambda_{2} \sin ^{2} \alpha \cos ^{2} \alpha\left(2 k_{2} m^{2}+1\right)
\end{aligned}
$$

The set of differential equations (6.1) is solved by the shooting method in Matlab with the boundary condition for $\lambda_{1}^{0}$ and $\lambda_{2}^{0}$ determined from the experiments. The results are at the following figures where calculated stretches and deformed profile of air-spring shell is compared with experimental one.

Fig. 5 describes the deformed profiles of cylindrical shell of air-spring under internal pressure $\mathrm{p}=0,5 \mathrm{MPa}$ with shortening length $15,20,30,40$ and $50 \mathrm{~mm}$. These results show that the deformation of material is large. The deformed profiles along the length of cylindrical shell subjected to different internal pressure are calculated and the results. respond well to experimental responses. 
Fig. 6 and 7 describe the axial and circumferential stretch with shortening length $15 \mathrm{~mm}$ under internal pressure $\mathrm{p}=0.4 \mathrm{MPa}$ and $0.5 \mathrm{MPa}$. The axial stretches in the cylindrical shell are less than 1 (shortening of the shell due to the inflation) and the circumferential stretches are greater than 1 . The numerical results show that the constitutive proposed material models are appropriate for the deformation analysis of the air-spring shell made from the given composite material.

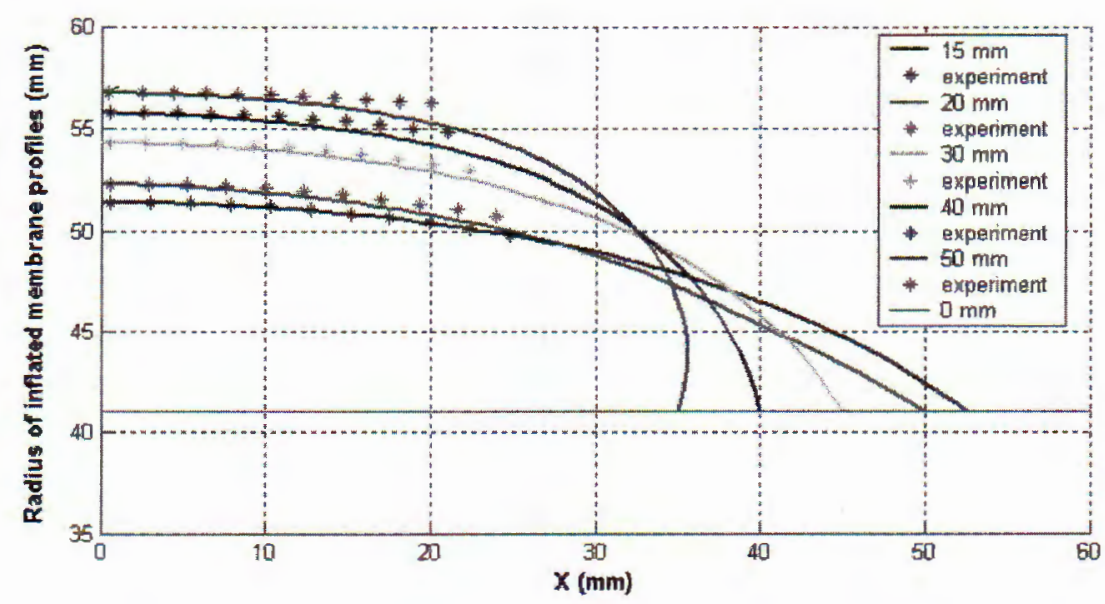

Fig. 5. The deformed profiles with shortening length 15, 20,30,40 and 50mm under internal pressure $p=0.5 \mathrm{MPa}$
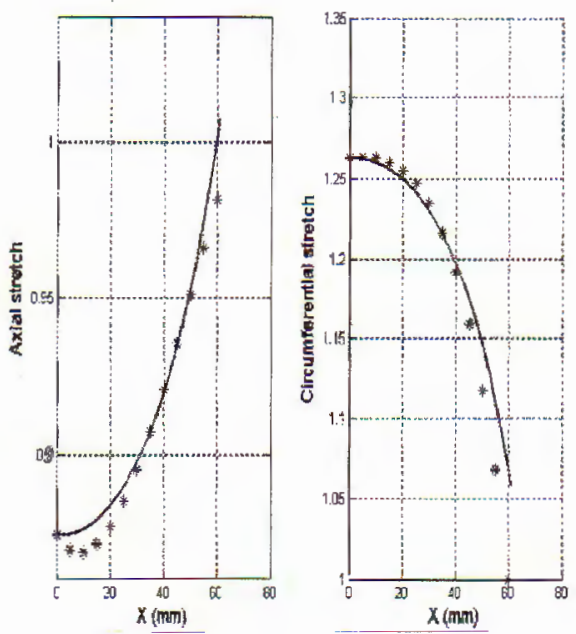

Fig. 6. The axial and circumferential stretch with shortening length $15 \mathrm{~mm}$ under internal pressure $p=0.4 \mathrm{MPa}$
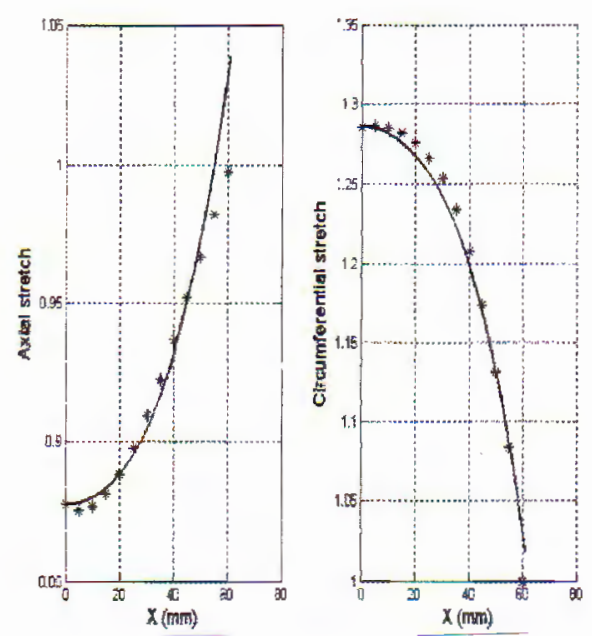

Fig. \%. The axial and circumferential stretch with shortening length $15 \mathrm{~mm}$ under internal pressure $\mathrm{p}=0.5 \mathrm{MPa}$

The examined air-spring is relatively short and the ends influence greatly its deformation. It is evident from the presented figures once the heads of the air-spring approach together the deformed shapes become curved broadly near the heads of air-spring. These 
curved parts cannot be measured directly experimentally as they are not visible at recorded photographs. Thus the difference at these points between the estimated reality and the numerical simulation is not alarming. Whereas the accordance of numerically simulated and experimentally measured stretches and shapes is satisfactory in the central portion of the air-spring.

\section{CONCLUSIONS}

This study was conducted in respect of the mechanical response of a thin-walled cylindrical shell of air-spring under combined inflation and axial force with reference to fundamental continuum mechanical principles. The problem of the identification of the material parameters was solved. The proposed strain energy function was implemented into the calculus of deformations of the inflated cylindrical air-spring shell. The deformations were determined by numerical solution to the system of ordinary differential equations based on the membrane theory. Numerical results for simulation of the inflated cylindrical membrane are obtained answering by experimental responses.

Acknowledgement. This publication is completed with financial support from the National Basic Research Program in Natural Science.

\section{REFERENCES}

1. M. F. Beatty, Topics in finite elasticity: Hyperelasticity of rubber, elastomers, and biological tissues with examples, Appl. Mech. Rev. 40 (12) (1987) 1699-1734.

2. J. Bonet, A. J. Burton, A simple orthotropic, transversely isotropic hyperelastic constitutive equation for large strain computations, Comput. Methods Appl. Mech. Engrg. 162 (1998) 151-164.

3. J. Bonet, M. L. Profit, Nonlinear viscoelastic constitutive modeling of a continuum, European Congress on Computational Methods in Applied Sciences and Engineering, Barcelona 11-14 September, 2000.

4. A. E. Green, J. E. Adkins, Bolšije Uprugie Deformaci i Nelinejnaja Mechanika Splošnoj Stredy, Moskva, 1965.

5. X. Guo, Large deformation analysis for a cylindrical hyperelastic membrane of rubber-like material under internal pressure, Rubber Chemistry and Technology 74 (2001) 100-115.

6. G. A. Holzapfel, T. C. Gasser, R. W. Ogden, A new constitutive framework for arterial wall mechanics and a comparative study of material models, Journal of Elasticity 61 (2000) 1-48.

7. G. A. Holzapfel, T. C. Gasser, A viscoelastic model for fiber-reinforced composites at finite strains: Continuum basis, computational aspects and applications, Comput. Methods Appl. Mech. Engrg. 190 (2001) 4379-4430.

8. G. A. Holzapfel, Nonlinear Solid Mechanics, John Wiley \& Sons Ltd, ISBN: 0-471-82319-8, Chichester West Sussex PO19, England, 2001.

9. B. Marvalova, R. Urban, Identification of orthotropic hyperelastic material properties of cordrubber cylindrical air-spring, Proc. of EUROMECH Colloquium 430, Prague, Czech Republic, October, 3-5, 2001.

10. B. Marvalova, R. Urban, Experimental analysis of deformation and stress of nonlinear orthotropic hyperelastic membrane, Proc. of $40^{\text {th }}$ conf. EAN 2002, Prague, Czech Republic, 304-309, 2002.

11. R.W. Ogden, Background on Nonlinear Elasticity, Lemaitre J., ed., in the handbook of materials behavior models, Chapter 2.2, Academic Press,Boston, 75-83, 2001. 
12. R. W. Ogden, C. A. J. Schulze-Bauer, Phenomenological and structural aspects of the mechanical response of arteries, Appeared as Proceedings in Mechanics in Biology, J. Casey and G. Bao, eds., AMD-Vol. 242, BED-Vol. 46, New York, 125-140, 2000.

13. A. Poživilová, J. Plešek, Elastomery: Konstitutivní Modelování, Identifikace Materiálových Parametr a Porounánús Experimentem, Inženýrká mechanika 2002, Svratka, eská Republika, 2002.

14. E. Verron, G. Marckmann, Inflation of elastomeric circular membranes using network constitutive equations, Int. J. of Non-Linear Mechanics 38 (2003) 1221-1235.

Received January 28, 2005

Revised May 12, 2005

\section{NHẬN DẠNG CÁC THAM SỐ CƯA MÔ HİNH VẬT LIỆU VÀ PHÂN TÍCH BIẾN DẠNG LỚN CỦA VỎ LÒ XO KHÍ NÉN LÀM BẰNG VẬT LỊ̂̂U COMPOSITE NỀN CAO SU CỐT SợI}

Trong bài báo này một mô hình trạng thái cho vật liệu siêu đàn hồi trực hướng được trình bày mà có thể ứng dụng cho mô phơng số những ứng xứ của mô mềm sinh học và vật liệu siêu đàn hồi trực hướng phi tuyến của vơ trụ lò xo khí nén dùng trong giảm chấn của ghế ôtô. Các tham số của hàm năng lượng biến dạng của mô hình trạng thái đề xuất được xác định từ những kết quả thực nghiệm bằng phương pháp bình phương nhỏ nhất phi tuyến. Biến dạng của vơ trụ căng phồng lò xo khí nén được tính toán bằng việc giải hệ năm phương trình vi phân thường với qui luật trạng thái vật liệu và các điệu kiện biên thích hợp. Các kết qưa số của độ dãn chính và biên dạng của vơ trụ căng phồng lò xo khí nén nhận được bằng cách phân tích biến dạng số và được so sánh với các kết quà thực nghiệm. 